\title{
Nutritional Treatment of Patients Operated on for Acute Mesenteric Ischemia
}

\author{
Timuçin Erol $^{1,2},[\mathrm{MD}]$ \\ ORCID: 0000-0002-3475-3639 \\ Şermin Ataç ${ }^{2}$, [MD] \\ ORCID: 0000-0002-2940-3714 \\ Kezban Akçay², [MD] \\ ORCID: 0000-0003-2848-3449 \\ Nilgün Ölmez ${ }^{2}$, [MD] \\ ORCID: 0000-0001-5823-8124 \\ Nezih Akapulu', [MD] \\ ORCID: 0000-0001-7392-961X \\ Ahmet Doğrul ${ }^{1}$, [MD] \\ ORCID: 0000-0001-9837-0787 \\ Osman Abbasoğlu ${ }^{1,2}$, [MD] \\ ORCID: 0000-0001-7069-929X
}

${ }^{1}$ Hacettepe University Faculty of Medicine Department of General Surgery

${ }^{2}$ Nutritional Support Department, Hacettepe University Hospital

Corresponding Author: Timuçin Erol

Hacettepe University Faculty of Medicine Department of General Surgery \& Nutritional Support Department, Hacettepe University Hospital.

Phone: +903123051676

E-mail: timucinerol@hacettepe.edu.tr

https://doi.org/10.32552/2021.ActaMedica.536

\section{n ABSTRACT Con}

Objective: Acute mesenteric ischemia is a surgical emergency. During the course of treatment, most of the patients require nutritional treatment. However, achieving nutritional goals may not be always possible. This study aimed to investigate nutritional management of the patients who were operated on for acute mesenteric ischemia.

Materials and Methods: Patients who were diagnosed and hospitalized for acute mesenteric ischemia between 2015 and 2018 were retrospectively analyzed. Nutritional management of patients was studied in terms of hospital length of stay, mortality rate and achieving of nutritional goals.

Results: Thirty patient were included in the study and 18 patient received nutritional treatment. Median length of stay was 28.5 (range:9-220) days. Target nutrition goals were only achieved in 11 patients (61\%). Overall mortality rate for nutritional treatment group was $50 \%$. There was no significant difference between the patients whose treatment objectives were achieved or failed in terms of length of stay $(p=0.375)$ or mortality $[(p=0.630(95 \% \mathrm{Cl} 0,237-10,809)]$.

Conclusion: The management of nutritional treatment of acute mesenteric ischemia patients is challenging. Achieving the nutritional goals may not be possible in many patients.

Keywords: Mesenteric ischemia, short bowel syndrome, parenteral nutrition

Received: 11 November 2020, Accepted: 15 March 2021,

Published online: 25 March 2021

\section{INTRODUCTION}

Acute mesenteric ischemia (AMI) is a sudden interruption of intestinal blood supply. Due to lack of collateral circulation, this situation often progresses to necrosis of bowel if early intervention is not performed. The incidence is quite low and diagnosis can be challenging. Delay in diagnosis is very common. Moreover, despite the utilization of endovascular techniques and appropriate surgical treatment, morbidity and mortality rates are still high even in patients with early diagnosis [1]. Ischemia and the accompanying necrosis necessitates surgical intervention and resection of the necrotic bowel. The extent of resection depends on the amount of the bowel affected and can result in short bowel syndrome. Even in limited resections, patients may require nutritional treatment during 
their hospital course. Most of these patients are old and have multiple co-morbidities which renders nutritional therapy even more challenging [2]. Under some circumstances, effective nutrition management may be more problematic due the patient's metabolic derangement. Interruptions of therapy and insufficient nutrient delivery are common problems in many patients [3].

In this study, we aimed to investigate the nutritional management of patients who were operated on for acute mesenteric ischemia in our center.

\section{MATERIALS and METHODS}

All patients diagnosed and hospitilised at general surgery department between 2015 and 2018 included to study included in this study. Patient's data retrospectively retrived from General Surgery Department data base which prospectively collect all operated patient's data. AMI was diagnosed by physical examination, laboratory tests, radiologic imaging, operative findings, and proved by histopathologic examination of resected bowel (Figure 1).

Patients' medical reports, operation notes, and prospectively recorded nutrition treatment follow up forms were analyzed retrospectively ( Figure 2) . Nutrition treatment aimed to reach $25 \mathrm{kcal} / \mathrm{kg} / \mathrm{d}$ energy and $1.5 \mathrm{gr} / \mathrm{kg} / \mathrm{d}$ protein to actual body weight. If the length of the remaining functional small bowel was less than $200 \mathrm{~cm}$, in accordance with European Society of Parenteral and Enteral Nutrition( ESPEN) definition and classification of
A

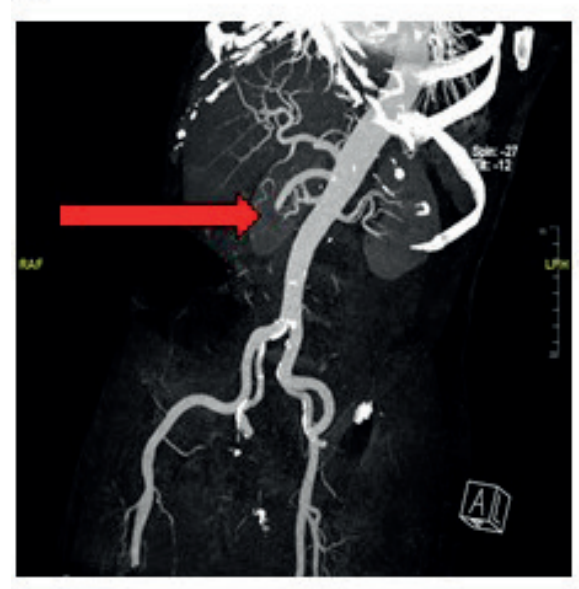

C

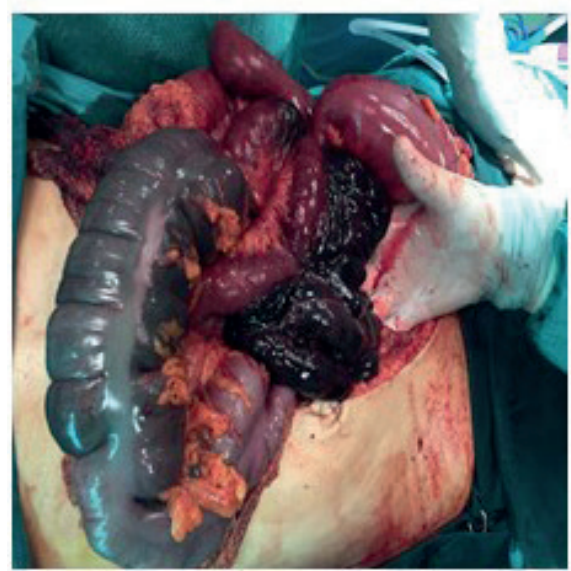

B

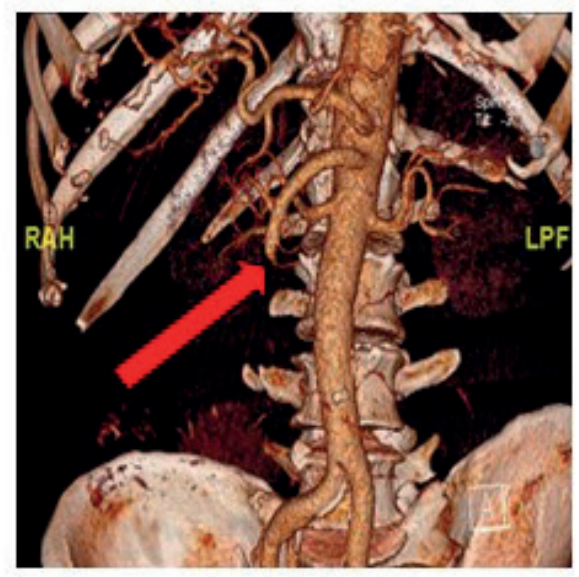

D

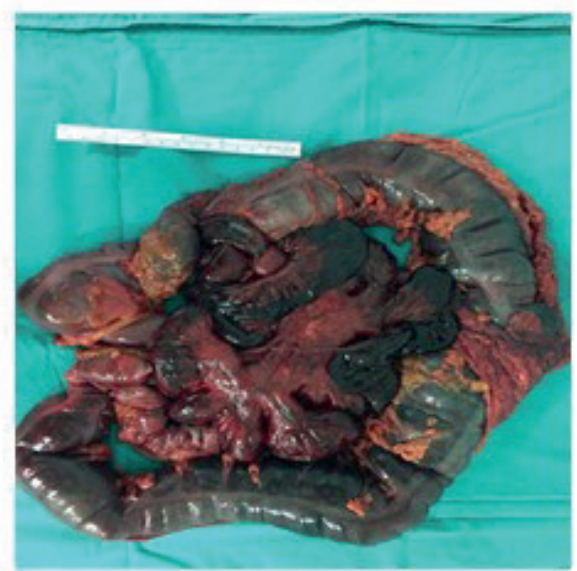

Figure 1. Preoperative imaging and intraoperative findings

A, B: Computerized tomography angiography and 3-D reconstruction images showing a case of total occlusion of superior mesenteric artery. Red arrow indicates the level of occlusion

C, D: Intraoperative appearance of ischemic bowel and specimen after resection. 

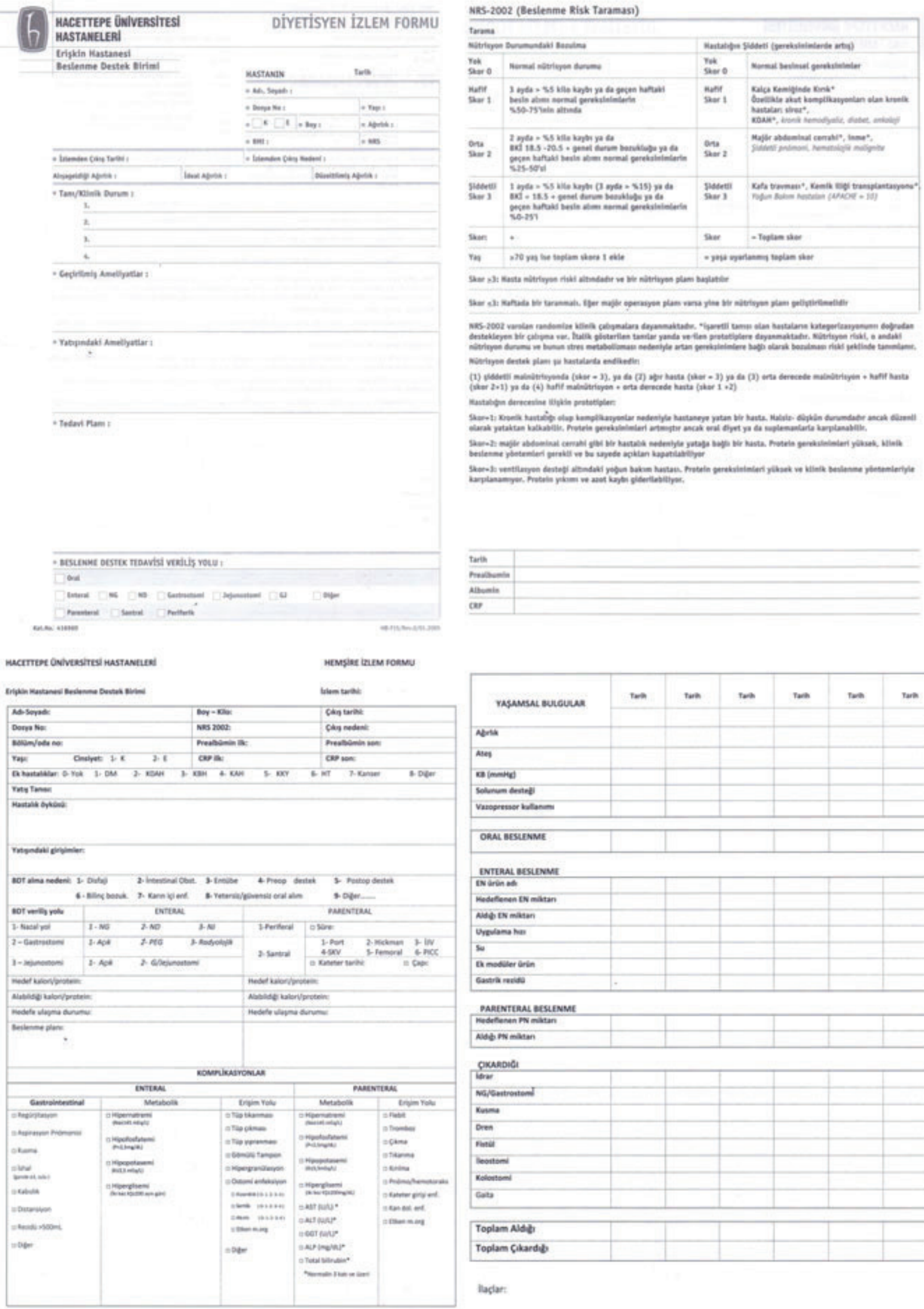

\begin{tabular}{|c|c|c|c|c|c|c|}
\hline vasemsal Evicucer & $+\infty$ & tom & $+\infty$ & tom & $+\infty$ & two \\
\hline \multicolumn{7}{|l|}{ Nom } \\
\hline \multicolumn{7}{|l|}{ Neen } \\
\hline \multicolumn{7}{|l|}{ aimoled } \\
\hline \multicolumn{7}{|l|}{ 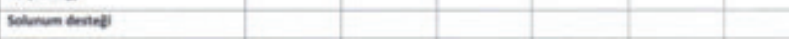 } \\
\hline \multicolumn{7}{|l|}{ 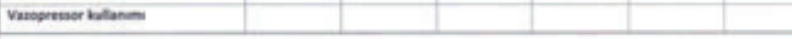 } \\
\hline \multicolumn{7}{|l|}{ ORAL BESLOAME } \\
\hline \multicolumn{7}{|l|}{ entroal aescionent } \\
\hline \multirow{2}{*}{\multicolumn{7}{|c|}{ Noringer }} \\
\hline & & & & & & \\
\hline \multicolumn{7}{|l|}{ Nas ex masen } \\
\hline \multicolumn{7}{|l|}{ Gedionorm } \\
\hline \multicolumn{7}{|l|}{$\infty$} \\
\hline \multicolumn{7}{|l|}{ a nowbertivin } \\
\hline costra menos & & & & & & \\
\hline \multicolumn{7}{|l|}{ DARENTILAL BesLeNme } \\
\hline \multicolumn{7}{|l|}{ 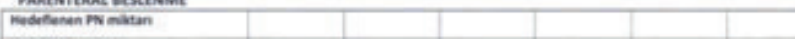 } \\
\hline \multicolumn{7}{|l|}{ Nate momitan } \\
\hline \multicolumn{7}{|l|}{ Qxwobiat } \\
\hline \multirow{2}{*}{\multicolumn{7}{|c|}{ Tarantronter }} \\
\hline & & & & & & \\
\hline \multicolumn{7}{|l|}{ sim } \\
\hline \multicolumn{7}{|l|}{ Dien } \\
\hline \multicolumn{7}{|l|}{ nem } \\
\hline \multicolumn{7}{|l|}{ rotion } \\
\hline \multicolumn{7}{|l|}{ resenten } \\
\hline \multicolumn{7}{|l|}{$\infty$} \\
\hline \multicolumn{7}{|l|}{ Toplam aldi } \\
\hline Toplam Sitaradd b & & & & & & \\
\hline
\end{tabular}

Figure 2 . Follow up forms 
intestinal failure in adults patients were classified as short bowel syndrome group [4]. Patients' demographic data, extent of surgery, intensive care unit and hospital length of stay (LOS), type of nutritional treatment, nutritional treatment duration, achieving nutritional goals, and 30-day and overall mortality rates were investigated.

SPSS software v23.0 (IBM Inc., Armonk, New York, USA) was used for statistical analysis. We used descriptive statics to analyze the demographic data; chi-squared tests were used for multiple proportions, and a $\mathrm{p}$-value $<0.05$ was considered significant. Continuous numerical variables were not normally distributed, and we presented them as the median value via the Mann-Whitney U-test. Categorical data were presented with frequency (\%) and compared by chi-squared testing.

Informed consent was obtained from the patients and the study was approved by Institutional Ethic Committee (GO16/65).

\section{RESULTS}

A total of 30 patients (19 males and 11 females) were diagnosed and hospitalized for AMI during the study period. Twenty-five patients had additional co-morbidities including atrial fibrillation, diabetes mellitus, deep venous thrombosis, mitral valve replacement, vasculitis, and malignancy. Twenty- nine patients were operated on due to $\mathrm{AMI}$, and one patient was followed up non- operatively with anticoagulation. Operative procedures were evaluated in three groups: 1. Massive small bowel \pm colon resection, 2 . Segmental small bowel \pm colon resection, and 3. other surgical procedures. After resection, intestinal anastomoses were performed in 16 patients while in the remaining operations were completed with an ostomy.

Patient characteristics and surgical procedures are summarized in Table 1.

The median hospital LOS was 20 days (range: 1-220) and median intensive care unit LOS was 6.5 days (range: 6-206). The 30-day mortality rate was $37.9 \%$ $(n=11)$, and the overall hospital mortality rate was $53.3 \%(n=16)$.

Eighteen patients received nutritional treatment during hospitalization, and the median duration of this treatment was 18 days (range: 3-128). Twelve patients did not receive any nutritional intervention due to early mortality $(n=6)$ and early return to oral intake $(n=6)$; the median length of stay in these patients was 11 days (range: 1-26). The operative mortality and overall mortality of patients receiving nutritional treatment were $27 \%(n=5)$ and $50 \%$ $(n=9)$, respectively. The median LOS of the patients receiving nutritional treatment was significantly higher than those who did not [28.5 (9-220) days and 11 (1-26) days respectively]. Parenteral

Table 1. Patient characteristics and surgical procedures

\begin{tabular}{|c|c|c|c|}
\hline $\begin{array}{l}\text { Patient } \\
\text { Characteristics }\end{array}$ & & Number (n) & Percentage (\%) \\
\hline Age (median, range) & $64(19-87)$ & & \\
\hline BMI & $26.8(15.0-35.1) \mathrm{kg} / \mathrm{m}^{2}$ & & \\
\hline \multirow{2}{*}{ Gender } & Male & 19 & $63 \%$ \\
\hline & Female & 11 & $37 \%$ \\
\hline \multirow[t]{6}{*}{ Co-morbidities } & Atrial fibrillation & 5 & $16 \%$ \\
\hline & Diabetes mellitus & 5 & $16 \%$ \\
\hline & Hypertension & 10 & $32 \%$ \\
\hline & Malignancy & 6 & $20 \%$ \\
\hline & Vascular diseases & 6 & $20 \%$ \\
\hline & Other diseases (Chronic renal failure, autoimmune diseases. etc.) & 11 & $36 \%$ \\
\hline \multicolumn{4}{|l|}{ Surgical procedures } \\
\hline & Massive small bowel \pm colon resection & 8 & $26 \%$ \\
\hline & Segmental small bowel \pm colon resection & 16 & $53 \%$ \\
\hline & $\begin{array}{l}\text { Other surgical procedures (Primary repair, total colectomy, } \\
\text { segmental colon resection) }\end{array}$ & 5 & $16 \%$ \\
\hline
\end{tabular}

BMI: Body mass index 
nutritional $(72 \%, \mathrm{n}=13)$ was the most commonly used route followed by enteral $(17 \%, n=3)$ and enteral plus parenteral combination $(11 \%, n=2)$.

For the patients receiving nutritional treatment, we aimed to reach $25 \mathrm{kcal} / \mathrm{kg} / \mathrm{d}$ energy and $1.5 \mathrm{gr} /$ $\mathrm{kg} / \mathrm{d}$ protein depending on the patient's general condition. These target levels were only achieved in 11 patients (61\%). The main reasons for the failure were fluid restriction and patient's hemodynamic instability. There was no significant difference between the patients whose treatment objectives were reached or failed in terms of LOS $(p=0.375)$ or mortality $[(p=0.630(95 \% C l 0,237-10,809)]$ (Table 2$)$.

In patients with short bowel syndrome, early mortality was seen in 1 of 8 patient (postoperative day 1 ). In addition to this, 4 patient died during the hospital course. Operative mortality rate was high as $62 \%(n=5)$. Five patients whose surgeries resulted in short bowel received only parenteral nutrition after clinical stabilization. All mortalities occurred in the parenteral nutrition group which progression to enteral or combined enteral plus parenteral nutrition was not possible.

\section{DISCUSSION}

Acute mesenteric ischemia is a surgical emergency with high mortality rates. To date no laboratory test can accurately diagnose the bowel ischemia or necrosis $[5,6]$. A high index of suspicion, early diagnosis, and prompt treatment are key factors for improved survival rates. Arterial emboli, thrombosis, venous infarction, and non-occlusive ischemia are the main causes of AMI [7]. Cardiac arrhythmia, endocarditis, vasculitis, cardiac failure, malignancies and hypercoagulability contribute to the disease process. Most patients have at least one co-morbidity as a risk factor for the development of bowel ischemia. Assessment of bowel viability by laparotomy or laparoscopy is indicated when overt peritoneal irritation signs are present. Reestablishment of vascular flow, resection of nonviable intestine, and preserving viable bowel are the main goals of surgery [8]. Unfortunately, most patients in our series required bowel resection due to bowel necrosis and endovascular or open surgical revascularization techniques were not be possible. Late admission and delay in diagnosis are the main causes of this condition.

In our study, majority of patients received parenteral route alone $(n=13,72 \%)$. This seems to be a deviation from recommendations. Guidelines recommend early enteral or combined nutrition for post-operative artificial nutrition after major abdominal surgery $[9,10]$. However, parenteral nutrition becomes necessary when enteral nutrition is not possible or inadequate due to impaired gastrointestinal function or presence of a high output stoma which are very common after surgery performed due to mesenteric ischemia. Two possible explanations of this high rate of parenteral route utilization in our study are; Patients whose operation resulted in short bowel syndrome require parenteral nutrition due to high stoma output or diarrhea at the early phase. Second, the high anastomosis rate and presence of intraabdominal infections may render the patients not to use enteral route for several days $(n=16)$.

Meticulous monitoring is crucial to avoid complications. Target levels of $25 \mathrm{kcal} / \mathrm{k} / \mathrm{d}$ energy and $1.5 \mathrm{gr} / \mathrm{kg} / \mathrm{d}$ protein may be slightly lower than the actual requirements [9]. On the other hand, over nutrition may which increase the energy expenditure, oxygen consumption and carbondioxide production and can be dangerous.

In this study, the patients who required parenteral nutrition have a longer LOS. Patients who did not receive nutritional treatment had little resections and could quickly return to oral intake. Those who survived the early post-operative period were prone to type II intestinal failure due to surgical trauma, pre-existing co-morbidities, and accompanying septic or metabolic complications $[11,12]$. These patients eventually need complex and long-term nutritional management, which prolongs the LOS [13].

Table 2. Mortality rates and length of stay of patients who received nutritional treatment.

\begin{tabular}{|l|c|c|}
\hline & Mortality (\%) & Median Length of Stay (range) \\
\hline Nutritional goals achieved $(n=11)$ & $6(54 \%)$ & 37 days (11-220) \\
Nutritional goals not achieved $(n=7)$ & $3(42 \%)$ & 25 days (9-93) \\
\hline
\end{tabular}


The main limitations of this study are small sample size and retrospective nature. Multicenter prospective trials are needed to establish adequate nutritional management of patients undergoing surgery for AMI.

\section{CONCLUSION}

The management of acute mesenteric ischemia patients is challenging. Nutritional treatment is one of the most crucial components of this treatment. Reaching the nutritional goals may not be possible in many patients. Individualized and meticulous nutrition treatment may help to improve patient management.

\section{CONFLICTS of INTEREST}

The authors declare that there is no conflict of interest.

\section{FUNDING}

None
[1] Eslami MH, Rybin D, Doros G et.al. Mortality of acute mesenteric ischemia remains unchanged despite significant increase in utilization of endovascular techniques. Vascular. 2016; 24(1): 44-52. doi:10.1177/1708538115577730

[2] Acosta S, Björck M. Acute thrombo-embolic occlusion of the superior mesenteric artery: A prospective study in a well defined population. EJVES. 2003; 26(2): 179-183. doi:https://doi.org/10.1053/ejvs.2002.1893

[3] Nurkkala J, Kaakinen T, Vakkala M, et.al. Factors associated with discrepancy between prescribed and administered enteral nutrition in general ICU. Eur J Clin Nutr. 2020; 74(2): 248-254. doi: 10.1038/s41430-019-0451-8. Epub 2019 Jun 13. PMID: 31197219.

[4] Pironi L, Arends J, Bozzetti F, et al. ESPEN guidelines on chronic intestinal failure in adults. Clin.Nutr. 2016; 35(2): 247-307. doi:https://doi.org/10.1016/j.clnu.2016.01.020

[5] Powell A, Armstrong P. Plasma biomarkers for early diagnosis of acute intestinal ischemia. Semin Vasc Surg. 2014; 27(3): 170-175. doi:https://doi.org/10.1053/j. semvascsurg.2015.01.008

[6] Evennett NJ, Petrov MS, Mittal A et.al. Systematic Review and Pooled Estimates for the Diagnostic Accuracy of Serological Markers for Intestinal Ischemia. journal article. World J Surg. 2009; 33(7): 1374-1383. doi:10.1007/s00268009-0074-7

[7] Bala M, Kashuk J, Moore EE, et al. Acute mesenteric ischemia: guidelines of the World Society of Emergency
Surgery. World J Emerg Surg. 2017; 12(1): 38. doi:10.1186/ s13017-017-0150-5

[8] Bala M, Kashuk J, Moore EE, et al. Acute mesenteric ischemia: guidelines of the World Society of Emergency Surgery. World J Emerg Surg. 2017; 12: 38-38. doi:10.1186/ s13017-017-0150-5

[9] McClave SA, Taylor BE, Martindale RG, et al. Guidelines for the Provision and Assessment of Nutrition Support Therapy in the Adult Critically III Patient: Society of Critical Care Medicine (SCCM) and American Society for Parenteral and Enteral Nutrition (A.S.P.E.N.). JPEN J Parenter Enteral Nutr. 2016; 40(2): 159-211. doi:10.1177/0148607115621863

[10] Weimann A, Braga M, Carli F, et al. ESPEN guideline: Clinical nutrition in surgery. Clin Nutr. 2017; 36(3): 623-650. doi:10.1016/j.clnu.2017.02.013

[11] Pironi L, Arends J, Baxter J, et al. ESPEN endorsed recommendations. Definition and classification of intestinal failure in adults. Clin Nutr. 2015; 34(2): 171-80. doi:10.1016/j.clnu.2014.08.017

[12] Park WM, Gloviczki P, Cherry KJ, et al. Contemporary management of acute mesenteric ischemia: Factors associated with survival. J Vasc Surg. 2002; 35(3): 445-452. doi:https://doi.org/10.1067/mva.2002.120373

[13] Klek S, Forbes A, Gabe S, et al. Management of acute intestinal failure: A position paper from the European Society for Clinical Nutrition and Metabolism (ESPEN) Special Interest Group. Clin Nutr. 2016; 35(6): 1209-1218. doi:10.1016/j.clnu.2016.04.009 